ISSN 0103-9954

\title{
PRODUÇÃO DE SERAPILHEIRA E TRANSFERÊNCIA DE NUTRIENTES EM FLORESTAS SECUNDÁRIAS LOCALIZADAS NA REGIÃO DE PINHEIRAL, RJ
}

\section{LITTER PRODUCTION AND MINERALS TRANSFER ON SECONDARY FORESTS IN PINHEIRAL REGION (RIO DE JANEIRO STATE)}

\author{
Luciano de Oliveira Toledo ${ }^{1}$ Marcos Gervasio Pereira ${ }^{2}$ Carlos Eduardo Gabriel Menezes ${ }^{3}$
}

\section{RESUMO}

Para a avaliação da deposição da serapilheira, foi conduzido um experimento em duas áreas de floresta secundária em diferentes graus de regeneração, floresta secundária inicial (FSI) e floresta secundária tardia (FST), no município de Pinheiral (RJ) no o ano de 1998. O aporte de serapilheira foi determinado por meio de coletores cônicos. A maior taxa de deposição de material decíduo, 4,03 t. ha ${ }^{-1}$, ocorreu na área de floresta secundária tardia (FST) no inverno. Em ambas as áreas, FST e FSI, a maior contribuição, em todas as estações, foi das folhas. Não foram verificadas diferenças na composição química do material decíduo entre estações.

Palavras-chaves: nutrientes, liteira, floresta secundária.

\begin{abstract}
An experiment was carried out to evaluate the contribution of the litter deposition under forest coverage in different stages of regeneration, initial secondary forest (ISF) and late secondary forest (LSF) in Pinheiral, RJ, in 1998. Litter deposition was measured in litter traps. The highest input of litter, 4.03 ton. ha ${ }^{1}$, was observed in LST, in winter. In both areas the highest input was verified in winter, and the leaves were the most important contributor. The chemical composition of litter did not show difference among the seasons.
\end{abstract}

Key words: nutrients, litter, secondary forest.

\section{INTRODUÇÃO}

No estudo da ciclagem de nutrientes, a quantificação das reservas minerais e orgânicas e suas transferências entre compartimentos são de extrema importância para compreender e comparar os diferentes ecossistemas e suas relações com o meio. No ecossistema florestal, essas reservas se acumulam na vegetação, nos animais, na serapilheira e no solo.

Os principais mecanismos responsáveis pela transferência de nutrientes da biomassa de espécies arbóreas para o solo são: a produção de serapilheira, a lavagem da vegetação pela chuva que extrai substâncias minerais e orgânicas das estruturas da parte aérea, e a decomposição da biomassa morta que inclui a serapilheira e raízes mortas (Sanchez, 1976; Gonzalez e Gallardo, 1986). Os fragmentos org ânicos, ao caírem sobre o solo, formam a camada denominada de serapilheira (Golley, 1978). Essa camada org ânica tem sido considerada um dos componentes importantes na ciclagem de nutrientes em ecossistemas florestais tropicais (Prittchet, 1979; Haag, 1987). A importância da serapilheira, para a ciclagem dos nutrientes em povoamentos florestais nativos ou implantados, é reconhecida desde o século passado. (Pritcehtt, 1979).

Quantidades significativas de nutrientes podem retornar ao solo pela queda de componentes senescentes da parte aérea de plantas e sua posterior decomposição.

Após a deposição do material decíduo, o seu acúmulo na superfície do solo será regulado pela sua taxa de decomposição (Haag, 1987). O mecanismo de decomposição é regulado sobretudo por três grupos de variáveis: a) a natureza da comunidade decompositora (os macro e microorganismos), b) as caracter ísticas

1. Engenheiro Florestal, Mestrando em Ciências Ambientais e Florestais, Universidade Federal Rural do Rio de Janeiro, CEP 23851-970, Seropédica (RJ). luctol@uol.com.br

2. Engenheiro Agrônomo, Dr., Professor Adjunto do Departamento de Solos, Instituto de Agronomia, Universidade Federal Rural do Rio de Janeiro, CEP 23890-000, Seropédica (RJ).gervasio@ufrrj.br

3. Engenheiro Florestal, M.Sc., Professor do Colégio Agrícola Nilo Peçanha e Universidade Federal Fluminense, CEP 23890-000, Seropédica (RJ). ceduardogm@uol.com.br

Recebido para publicação em 22/10/2001 e aceito em 5/07/2002. 
do material orgânico que determinam sua degradabilidade (a qualidade do material) e c) as condições do ambiente (Aber e Melilo, 1978).

Embora venham sendo realizados trabalhos visando a quantificar o aporte de serapilheira em ecossistemas florestais (Peres et al., 1983; Brietz et al., 1997; Barbosa, 2000), poucos são aqueles que comparam a taxa de deposição em florestas secundárias com diferentes graus de revegetação.

Este trabalho teve como objetivo avaliar a deposição de material decíduo em florestas secundárias no município de Pinheiral - RJ, bem com quantificar a entrada de nutrientes nesses ecossistemas.

\section{MATERIAL E MÉTODOS}

\section{Meio Físico}

O estudo foi realizado no município de Pinheiral - RJ, localizado entre as latitudes $22^{\circ} 30^{\prime} \mathrm{S}$ e $22^{\circ} 38^{\prime}$ 'S e entre as longitudes $43^{\circ} 57^{\prime} \mathrm{W}$ e $44^{\circ} 05^{\prime} \mathrm{W}$, na região do Médio Vale do Paraíba do Sul (Projeto RADAMBRASIL, 1983). A região apresenta relevo denominado por "mar de morros" com a altitude variando entre 360 e 720 metros. O clima é classificado como temperado de inverno seco e verão chuvoso, tipo Cwa, segundo a classificação de Köppen. A temperatura média máxima é de $30,9^{\circ} \mathrm{C}$ em janeiro e a média mínima de $16,8^{\circ} \mathrm{C}$ em julho. A média anual encontra-se em torno de $22^{\circ} \mathrm{C}$. A precipitação varia entre 1300 a $1500 \mathrm{~mm} / \mathrm{ano}$, com excedente hídrico de 100 a $150 \mathrm{~mm}$ mensais de dezembro a março, sendo verificada deficiência hídrica de julho a setembro.

Quanto ao histórico de utilização, a primeira forma de uso da área foi a agricultura extrativista, sendo posteriormente substituída, no período colonial, pela cultura do café. Progressivamente, as lavouras cafeeiras foram substituídas pela pecuária leiteira e pela pecuária de corte, sendo a última de maior expressão e caracterizada por ocupar grandes áreas de pastagens naturais ou implantadas e pelo pequeno uso de mão-de-obra. Em razão dessas diferentes formas utilização, são observadas no município grandes extensões de áreas em vários estágios de degradação, encontrando-se em alguns pontos manchas de vegetação secundária em regeneração com o aspecto de ilhas em meio à predominância de pastagens degradadas, nativas e plantadas (Figura 1).
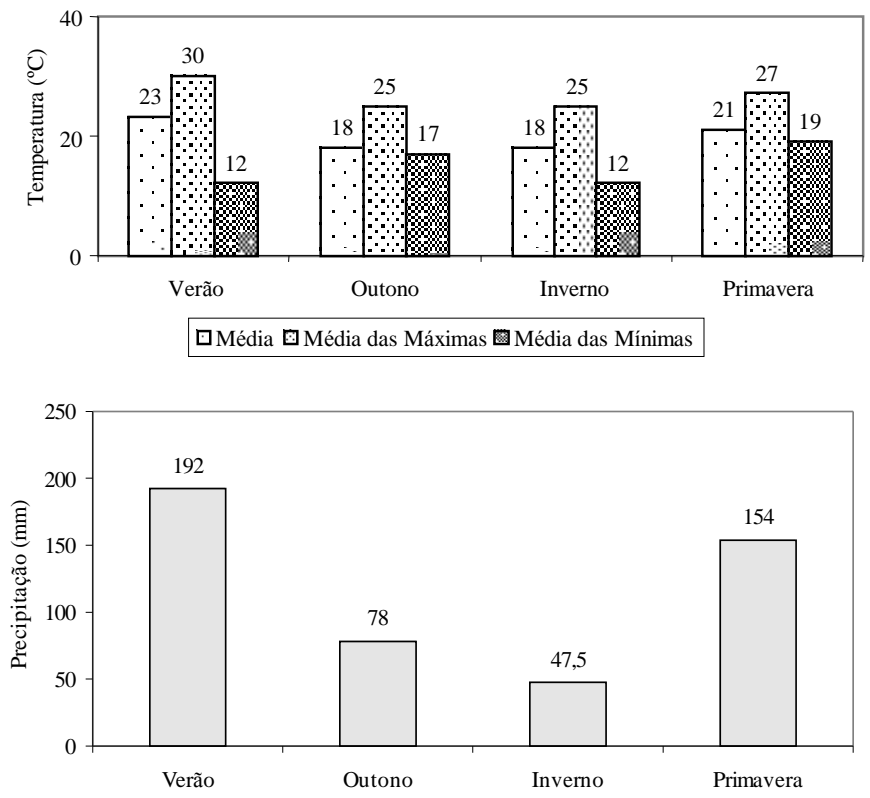

FIGURA 1: Normais Climatológicas de Piraí, Temperatura e Precipitação Pluviométrica.Fonte: Barbiérie e Kronemberger (1994), modificado de Oliveira (1998).

FIGURE 1: Weather Normal of Piraí, Temperature and Rain Precipitation. Fonte: Barbiérie and Kronemberger (1994), modified by Oliveira (1998). 
Para o estudo, foram selecionadas duas áreas de florestas secundárias, a saber: floresta secundária inicial (FSI), com aproximadamente 10 anos de regeneração, e floresta secundária tardia (FST), com aproximadamente 50 anos de regeneração. Essas áreas foram escolhidas com base no estudo de Oliveira (1998), na região de Pinheiral (RJ), no qual se identificaram sete unidades de paisagens diferentes, estando a FSI e a FST, entre as áreas de estágios sucessão mais evoluídos.

Para a seleção das áreas, foram consideradas sua homogeneidade quanto ao relevo, à posição na encosta (terço médio), no comprimento e à forma da pendente, e ao tipo de solo.

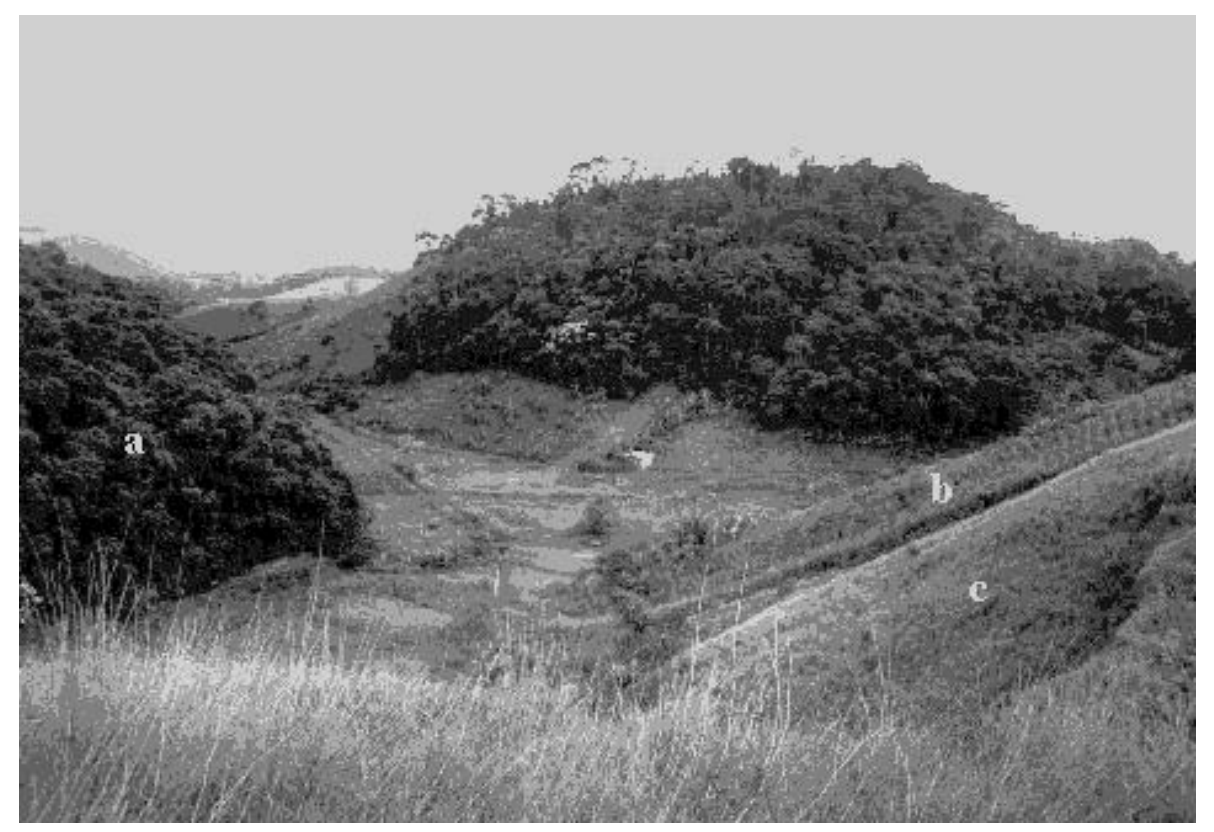

FIGURA 2: Principais coberturas vegetais verificadas na região de Pinheiral: (a) floresta secundária, (b) agricultura e (c) pastagem.

FIGURE 2: Principal main vegetation coverage verified in Pinheiral region: (a) secondary forest, (b) agriculture and (c) field.

Os solos identificados nas áreas de estudo enquadram-se ma classificação de Argissolo Vermelho Amarelo Álico Tb, classe predominante na área da antiga Fazenda Pinheiros. Esses solos, por terem sido formados partindo da ação do intemperismo sobre rochas ácidas, sobretudo gnaisse e pelo relevo predominante de encostas com declividade variando de 35 a $70 \%$, têm as seguintes características: avançado grau de intemperismo, drenagem moderada e acentuada, facilmente erodíveis e em geral pouco férteis. Essas características aliadas ao manejo inadequado das áreas cultivadas são responsáveis pelo alto índice de degradação. Entre as propriedades, que podem ser usadas para avaliar esse grau de degradação, destacam-se a espessura do horizonte A e do solum.

\section{Métodos}

\section{Material decíduo}

Nas áreas de floresta, foram instalados dez coletores cônicos, nos quais foram realizadas coletas mensais do material decíduo depositado. O material foi seco em estufa, estratificado em folhas, flores, galhos, frutos, cascas e outros e pesado com o objetivo de avaliar a contribui ção de cada uma das frações em cada estação. Após essa etapa, todo material decíduo foi homogeneizado, obtendo-se uma amostra que foi triturada e submetida à digestão nitro-perclórica (Tedesco et al., 1995). No extrato, foram determinados os teores de N, P, K, Ca, Mg, Fe, Cu, Zn e Mn. 


\section{RESULTADOS E DISCUSSÃO}

A massa de folhedo adicionado ao solo durante o ano de 1998 foi de 12,97 ton ha ${ }^{-1}$ na área de FST, já na área FSI, a quantidade de material decíduo depositado foi de 10,46 ton ha ${ }^{-1}$. Em literatura, verificam-se quantidades de material aportado, variando de 4 a $25 \mathrm{t} \mathrm{ha}^{-1}$, para florestas tropicais em geral (UNESCO, 1978, Golley et al. 1978). Em média, nas florestas tropicais sobre solos de baixa fertilidade, verificam-se depósitos de 7,5 ton ha ${ }^{-1}$ de matéria seca na forma de resíduos orgânicos formadores da serapilheira, enquanto que, em solos de fertilidade média, essa produção é de 10,5 ton ha ${ }^{-1}$ e em áreas montanhosas de 6,3 ton $\mathrm{ha}^{-1}$ (Andrade, 1997).

A maior taxa de deposição do material decíduo ocorreu na área de FST durante o inverno $\left(4,03\right.$ t ha ${ }^{-}$ ${ }^{1}$ ), sendo tal deposição maior que na área FSI na mesma época $\left(2,91 \mathrm{t} \mathrm{ha}^{-1}\right)$ (Figura 2). Comportamento similar, quanto à sazonalidade, foi observado por Silva (1982); Peres et al. (1983) e Swamy e Proctor (1994), demostrando que não só a precipitação total, mas também a distribuição das chuvas ao longo do ano influencia na taxa de deposição de material decíduo. As temperaturas médias apresentaram-se mais baixas na estação do inverno, o que também pode ter contribuído para a maior deposição de material decíduo da área de FST. O efeito da sazonalidade na deposição da serapilheira é bem discutido por Dias e Oliveira Filho (1997), em que, segundo os autores, maior produção, nos meses mais frios e secos do ano, seria uma característica típica de florestas tropicais estacionais e, ao contrário, maior deposição ocorrendo na transição entre a estação seca e a estação chuvosa, seria típico de regiões tropicais e subtropicais.

De acordo com a Figura 3, durante a primavera, a área de FST acumulou 1,65 $\mathrm{t} \mathrm{ha}^{-1} \mathrm{e}$ a área de FSI, $1,97 \mathrm{t} \mathrm{ha}^{-1}$. Esses resultados, observado o aumento normal na incidência de precipitação pluviométrica do inverno para a primavera (de $47,5 \mathrm{~mm}$ para $154 \mathrm{~mm}$ respectivamente), apontam para uma queda brusca na taxa de deposição de material decíduo, o que pode ser explicado pela restaura ção da folhagem arbórea após o fenômeno de senescência, característico das espécies que compõem tais florestas (Floresta Estacional Semidecidual).

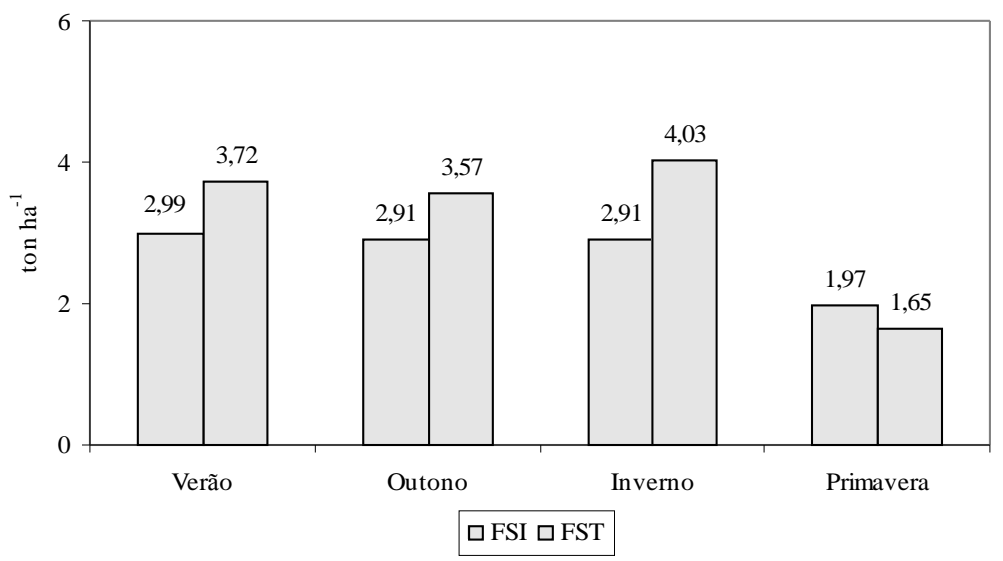

FIGURA 3: Material decíduo adicionado ao longo de 1998.

FIGURE 3: Litter felled accumulated in the year of 1998.

As estratificações do material decíduo, durante as diferentes estações do ano (Figura 4 a Figura 7), demonstram que a unidade anatômica vegetal que mais contribui na formação da serapilheira é a folha, seguida dos ramos. A contribuição das demais unidades (flores, frutos e cascas) oscila em torno de valores sempre inferiores às folhas e/ou aos ramos. Vários estudos demostram que um dos principais constituintes da serapilheira são as folhas que podem contribuir em até $70 \%$ do material adicionado (Proctor, 1983; Morellato, 1992; Barbosa, 2000).

Foram observadas algumas variações, quanto à composição química do material decíduo, nos teores de nutrientes entre estações. Entre os micronutrientes, o ferro foi o que apresentou as maiores variações. Também foram verificadas diferenças no conteúdo de cobre na primavera e de manganês no outono. Para os 
macronutrientes, observou-se um aumento no teor de potássio na estação de inverno (Tabela 1). Esse último caso certamente reflete o fato desse nutriente $\mathrm{n}$ ão fazer parte de nenhum componente estrutural da planta, passando rapidamente para a solução do solo, uma vez que o material decíduo se deposita sobre a serapilheira. Os dados de nutrientes aportados ao solo (Tabela 2 e 3 ) indicam uma baixa taxa de ciclagem.

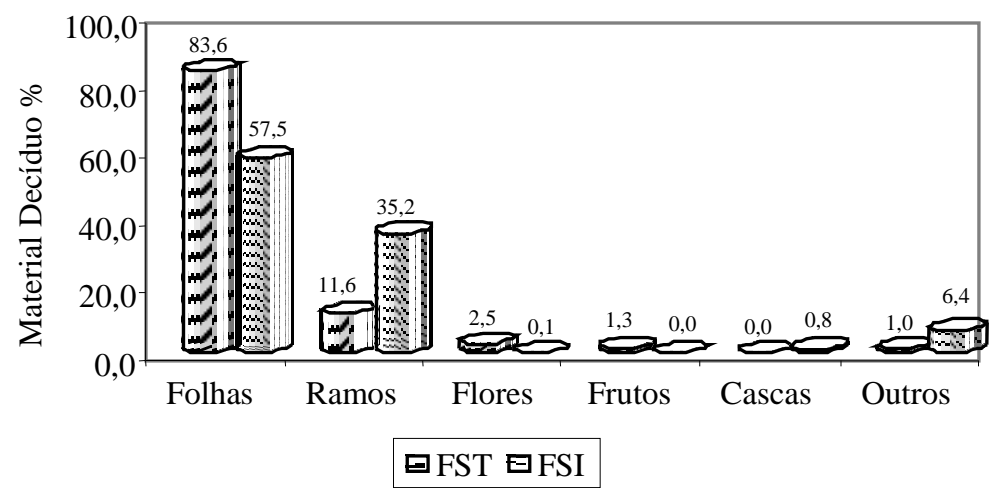

FIGURA 4: Material decíduo em FST E FSI no inverno.

FIGURE 4: Litter felled in late secondary forest (FST) and initial secondary forest (FSI) in the winter season.

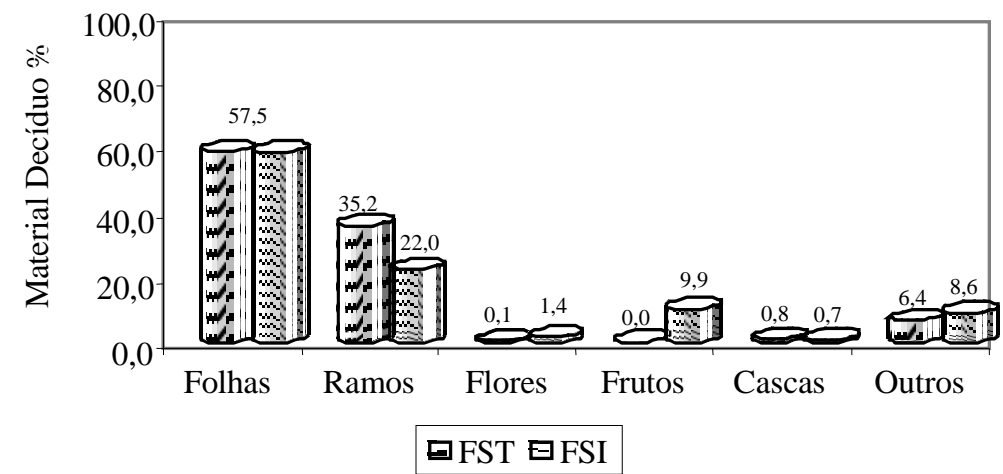

FIGURA 5: Material decíduo em FST E FSI na primavera.

FIGURE 5: Litter felled in late secondary forest (FST) and initial secondary forest (FSI) in the spring season.

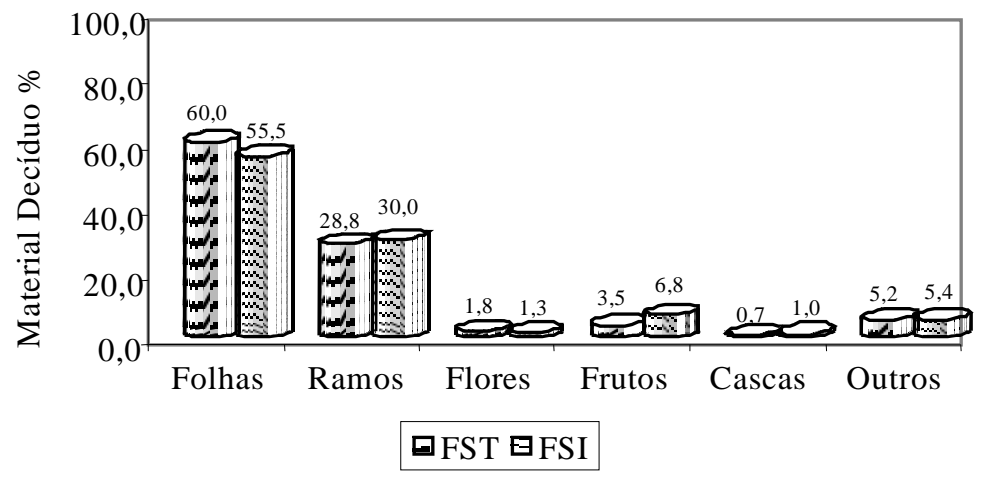

FIGURA 6: Material decíduo em FST E FSI no verão.

FIGURE 6: Litter felled in late secondary forest (FST) and initial secondary forest (FSI) in the summer season. 


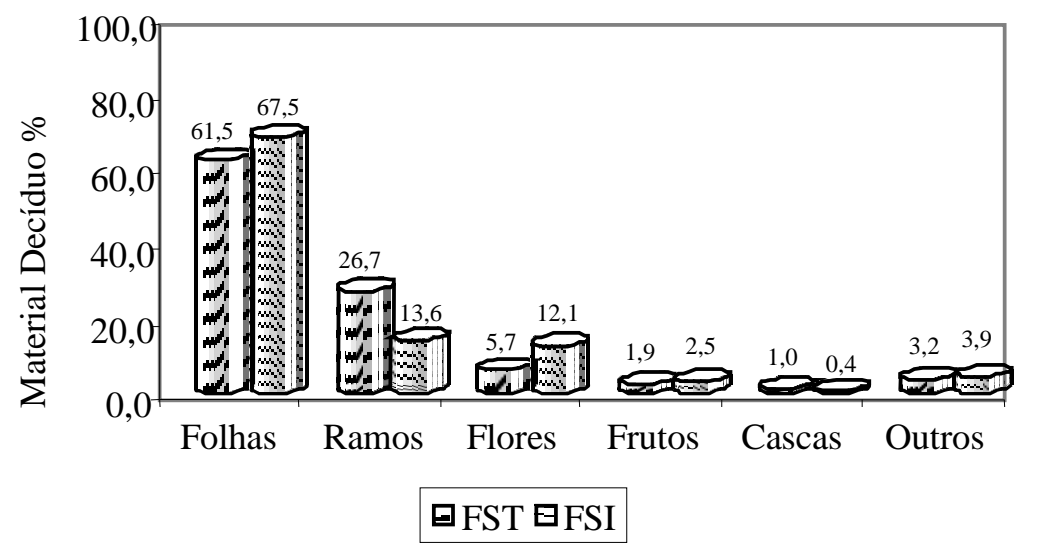

FIGURA 7: Material decíduo em FST E FSI no outono.

FIGURE 7: Litter felled in late secondary forest (FST) and initial secondary forest (FSI) in the autumn season.

Anualmente, são depositados, na serapilheira da FST, com a queda do material decíduo, cerca de $218,9 \mathrm{~kg} \mathrm{ha}^{-1}$ de nitrogênio, 5,8 $\mathrm{kg} \mathrm{ha}^{-1}$ de fósforo, $67,4 \mathrm{~kg} \mathrm{ha}^{-1}$ de potássio, $107,7 \mathrm{~kg} \mathrm{ha}^{-1}$ de cálcio e $37,6 \mathrm{~kg}$ $\mathrm{ha}^{-1}$ de magnésio. Já na área FSI, observam-se menores valores: $165,5 \mathrm{~kg} \mathrm{ha}^{-1}$ de nitrogênio, $5,4 \mathrm{~kg} \mathrm{ha}^{-1} \mathrm{de}^{-1}$ fósforo, $50,1 \mathrm{~kg} \mathrm{ha}^{-1}$ de potássio, $88,9 \mathrm{~kg} \mathrm{ha}^{-1}$ de cálcio e $29,1 \mathrm{~kg} \mathrm{ha}^{-1}$ de magnésio. Comparados com outras florestas tropicais (Golley et al., 1978; UNESCO, 1978; Sampaio et al., 1988), esses resultados são altos para todos os nutrientes. Sendo, em muito, superiores aos encontrados para a floresta amazônica, onde os valores foram 14, 11, 11, e $2 \mathrm{~kg} \mathrm{ha}^{-1}$ ano $^{-1}$ (Klinge e Rodrigues 1968) e 18, 13,13 e 2 (Schubart et al., 1984), para o $\mathrm{Ca}, \mathrm{K}, \mathrm{Mg}$ e $\mathrm{P}$, respectivamente.

Quanto aos micronutrientes, os maiores teores encontrados foram de ferro, seguido pelo mangan ês e os menores foram para o cobre e o zinco. Sampaio et al. (1978), estudando a ciclagem de nutrientes na mata de Dois Irmãos, Recife, Pernambuco, observou teores semelhantes em relação ao conteúdo de ferro adicionado pelo material decíduo, porém menores valores do elemento manganês.

TABELA 1: Análises de macro e micronutrientes no tecido vegetal (folhas, ramos, flores, frutos, cascas e outros).

TABLE 1: Macro and micro nutrients analysis in vegetal tissue (leaf, branch, flower, fruit, bark and others).

\begin{tabular}{|c|c|c|c|c|c|c|c|c|c|}
\hline Área & $\mathrm{N}$ & $\mathrm{P}$ & $\mathrm{K}$ & $\mathrm{Ca}$ & $\mathrm{Mg}$ & $\mathrm{Fe}$ & $\mathrm{Cu}$ & $\mathrm{Zn}$ & $\mathrm{Mn}$ \\
\hline & \multicolumn{5}{|c|}{$\%$} & \multicolumn{4}{|c|}{$\mathrm{mg} \mathrm{g}^{-1}$} \\
\hline \multicolumn{10}{|c|}{ Inverno } \\
\hline FST & 1,62 & 0,04 & 0,88 & 0,72 & 0,30 & 500 & 8 & 44 & 485 \\
\hline FSI & 1,33 & 0,04 & 0,72 & 0,76 & 0,22 & 520 & 12 & 50 & 565 \\
\hline \multicolumn{10}{|c|}{ Primavera } \\
\hline FST & 1,95 & 0,06 & 0,30 & 0,94 & 0,30 & 1200 & 28 & 62 & 575 \\
\hline FSI & 1,46 & 0,04 & 0,37 & 0,78 & 0,26 & 720 & 56 & 64 & 665 \\
\hline \multicolumn{10}{|c|}{ Verão } \\
\hline FST & 1,35 & 0,04 & 0,39 & 0,86 & 0,26 & 600 & 16 & 76 & 695 \\
\hline FSI & 1,89 & 0,06 & 0,31 & 0,92 & 0,30 & 1980 & 16 & 74 & 570 \\
\hline \multicolumn{10}{|c|}{ Outono } \\
\hline FST & 1,83 & 0,04 & 0,51 & 0,80 & 0,30 & 900 & 28 & 62 & 575 \\
\hline FSI & 1,46 & 0,06 & 0,46 & 0,84 & 0,30 & 620 & 16 & 60 & 7455 \\
\hline
\end{tabular}

Em que: FSI = floresta secundária inicial; FST = floresta secundária tardia. 
TABELA 2: Quantidade média de macronutrientes aportados ao solo das diferentes áreas no ano de 1998. TABLE 2: Average of macro nutrients transferred to the soil in different areas in 1998.

\begin{tabular}{c|c|c|c|c|c}
\hline \multirow{2}{*}{ Área } & $\mathrm{N}$ & $\mathrm{P}$ & $\mathrm{K}$ & $\mathrm{Ca}$ & $\mathrm{Mg}$ \\
\cline { 2 - 6 } & \multicolumn{5}{|c|}{$\mathrm{kg} \mathrm{ha}^{-1}$ ano } \\
\hline FST & 218,9 & 5,8 & 67,4 & 107,7 & 37,6 \\
FSI & 165,5 & 5,4 & 50,1 & 88,9 & 29,1 \\
\hline
\end{tabular}

Em que: FSI = floresta secundária inicial; FST = floresta secundária tardia.

TABELA 3: Quantidade média de micronutrientes aportados ao solo das diferentes áreas no ano de 1998. TABLE 3: Average of micro nutrients transferred to the soil in different areas in 1998.

\begin{tabular}{c|c|c|c|c}
\hline \multirow{2}{*}{ Área } & $\mathrm{Fe}$ & $\mathrm{Cu}$ & $\mathrm{Zn}$ & $\mathrm{Mn}$ \\
\cline { 2 - 5 } & \multicolumn{4}{|c|}{$\mathrm{g} \mathrm{ha}^{-1} \mathrm{ano}^{-1}$} \\
FST & 10,6 & 0,27 & 0,81 & 7,74 \\
FSI & 10,0 & 0,26 & 0,65 & 6,65 \\
\hline
\end{tabular}

Em que: FSI = floresta secundária inicial; FST = floresta secundária tardia.

\section{CONCLUSÕES}

O fato do ecossistema primário regional ser de Floresta Estacional Semidecidual, onde as árvores, de uma maneira geral, perdem parte da folhagem na estação de maior estresse hídrico, mostra que as duas áreas apresentam-se em estágios diferentes de sucessão. A maior taxa de deposição de material decíduo foi constatada na área de floresta secundária tardia (FST), na estação de inverno. Porém, a área de floresta secundária inicial (FSI) não apresentou o mesmo comportamento, caracterizando seu estágio atual de pouco desenvolvimento em relação à outra área.

A unidade anatômica vegetal de maior relevância na formação da serapilheira é a folha. Dessa forma, pode-se afirmar que uma análise detalhada do comportamento dessa unidade caracteriza, com grande confiabilidade, a dinâmica de material decíduo e a ciclagem de nutrientes em áreas de Floresta Estacional Semidecidual.

Não foram verificadas relevantes diferenças nos conteúdos de nutrientes aportados ao solo entre as quatro estações do ano de 1998.

\section{REFERÊNCIAS BIBLIOGRÁFICAS}

ABER, J.D.; MELILO, J.M. Terrestrial ecossystems. Orlando, FL.:Reinhart e Wintson, 1978. 428p.

ANDRADE, A. G. Ciclagem de nutrientes e arquitetura radicular de leguminosas arbóreas de interesse para revegetação de solos degradados e estabilização de encostas. 1997. 182p. Tese (Doutorado em Ciência do Solo) Universidade Federal Rural do Rio de Janeiro, Seropédica.

BARBOSA, J. H. C. Dinâmica da serapilheira em estágios sucessionais de Floresta Atlântica (Reserva Biológica de Poço das Antas - RJ). 2000. 202p. Dissertação (Mestrado em Ciência do Solo) - Universidade Federal Rural do Rio de Janeiro, Seropédica.

BRITEZ, R.M.; SANTOS FILHO, A.; REISSMANN, C.B. et al. Nutrientes no solo de duas florestas da planície litorânea da Ilha do Mel., Paranaguá, PR. Rev. Bras. Ci. Solo, Viçosa, v. 21, n. 4, p. 625-634, 1997.

GOLlEY, F. B.; MC GINNIS, J. T.; CLEMENTS, R. G.; et al. Ciclagem de minerais em um ecossistema de floresta tropical úmida. São Paulo: Pedagógica e Universitária, 1978. 256p.

GONZÁLEZ, M.I.M.; GALLARDO, J.F. El efecto hojarasca: una revisión. Anales de edafología y agrobiología. p. 1130-1157, 1986.

HAAG, H. P. A nutrição mineral e o ecossistema. In: CASTRO, P.R.C.; FERREIRA, S.O.; YAMADA, T. Ecofisiologia da produção agrícola. Piracicaba: Associação Brasileira para Pesquisa da Potassa e do Fosfato. 1987. p. 49-52.

KLINGE, H. P.; RODRIGUES, W.A. Litter production in area of Amazonian "terra firme"forest. Part II. Mineral nutrient content of litter. Amazoniana, n. 1, p. 303-310, 1968.

OLIVEIRA, J. A. Caracterização física da Bacia do Ribeirão Cachimbal - Pinheiral, RJ e suas principais 
paisagens degradadas. 1998. 143p. Dissertação (Mestrado em Ciências do Solo) - Universidade Federal Rural do Rio de Janeiro, Seropédica.

PERES, J. R.R.; SUHET, A. R.; VARGAS, M. A. T. et al. A produção de resíduos vegetais em áreas de cerrado do Brasil. Pesq. Agropec. Bras., Brasília, v. 18, p. 1037-1043, 1983.

PRITCHETT, W. L. Properties and management of forest soils. New York: John Wiley and Sons, 1979. 500p.

PROCTOR, J. Tropical forest litterfall. I. Problems of data comparasion. In: SUTTON, S.L.; WHITMORE, T.C.;

CHADWICK, A.C. Tropical rain forest: ecology and management. Special publications series of Britsh Ecological Society. III Decomposition and nutrient cycling. 1983. p. 267-273.

PROJETO RADAMBRASIL. Folhas SF 23/24. Rio de Janeiro/Vitória: geologia, geomorfologia, pedologia, vegetação e uso potencial da terra. Rio de Janeiro, 1983. 446p. (Levantamento de Recursos Naturais, 32).

SAMPAIO, E. V. S. B.; NUNES, K. S.; LEMOS, E. P. Ciclagem de nutrientes na mata de Dois Irmãos (Recife - PE) através da queda de material vegetal. Pesq. Agropec. Bras., Brasília, v. 23 n. 10, p. 1055-1061, 1988.

SANCHEZ, P. A. Properties and management of soils in the tropics. New York: John Wiley and Sons, 1976. 409p

SCHUBART, H. O. R.; FRANKEN, N.; LUIZÃO, F. J. Uma floresta sobre solos pobres. Ci. Hoje, n. 2, p. 26-32, 1984.

SILVA, M. F. F. Produção anual de serapilheira e seu conteúdo mineralógico em mata tropical de terra firme na área do rio Tocantins, Pará. 1982. 78p. Dissertação (Mestrado em Ciência Florestal) - INPA/FUA, Manaus.

SWAMY, H. R.; PROCTOR, J. Litterfall and nutrient cycling in four rain forests in the Sringeri area of the Indian Western Ghats. Global Ecology and Biogeography Letters, v. 4, p. 155-165, 1994.

TEDESCO, J.; GIANELlO, C.; BISSANI, C. A.; BOHNEN, H. e VOLKWEISS, S.J. Análises de solo, planta e outros materiais. 2. ed. rev. e ampl. Porto Alegre: Departamento de Solos, UFRGS. 1995. 174p.

UNESCO. Paris, França. Tropical forest ecosystems: a state of knowledge. Paris, UNEP/FAO, 1978. p. 233-288. (Natural Resources Research XIV) 